\title{
"Lo caliente" como fortalecedor del sistema inmunológico durante la pandemia Covid-19: consumo de alimentos en el entorno urbano
}

"Comida quente" como um reforço do sistema imunológico durante a pandêmica Covid-19: consumo de alimentos no ambiente urbano

"Hot food" as a strengthener of the immunological system during the pandemic Covid-19: food consumption in the urban environment

Marisa Josefina Valadez Montes ${ }^{1}$, Claudia Talía Cardona²

\section{RESUMEN}

El objetivo de este artículo es analizar las prácticas alimentarias durante la pandemia Covid-19 en una provincia del centro-occidente mexicano. En este contexto el consumo de alimentos se ha distinguido por la predilección de caldos y guisos que son considerados por la población como fortalecedores del sistema inmunológico. Se establece una relación entre lo caliente y el mayor rendimiento de las "defensas" en el cuerpo, de manera que durante la pandemia se prefieren las consistencias caldosas "gruesas" o a altas en lípidos acompañadas de legumbres, en vez de lípidos saturados como el Chicharrón de cerdo, las birrias ${ }^{3}$, etc. Si bien el consumo de alimentos calientes es parte de los valores y símbolos sobre el cuerpo y la alimentación en México, en este documento también lo planteamos como parte de la acción social que se inscribe en actos cotidianos, que resurgen en un contexto de crisis e incertidumbre sanitaria y económica. La presente examinación se hace mediante una colaboración interdisciplinaria desde la mirada de la nutrición y la antropología, las cuales nos permiten presentar un escenario más amplio con relación a las prácticas alimentarias de la gente. Para ello, acudimos al estudio de caso de un paciente recuperado de COVID-19, así como la etnografía del consumo de alimentos en un mercado de una zona urbana popular.

Palabras Clave: Covid-19; Alimentación; Caldos

\section{RESUMO}

O objetivo deste artigo é analisar as práticas alimentares durante a pandemia Covid19 em uma província no centro-oeste do México. Nesse contexto, o consumo alimentar tem se destacada pela predileção de caldos e ensopados que são

\footnotetext{
1 Universidad Autónoma de Aguascalientes, México. https://orcid.org/0000-0002-3317-5638. E-mail: marisa.valadezm@gmail.com

2 Instituto Mexicano del Seguro Social (IMSS). México. E-mail: talia.cardona@gmail.com

3 Platillo que se prepara en varias regiones de México a base de carne de borrego o carnero, chivo o res adobado. Se prepara a base de algunos tipos de chiles y tradicionalmente se cuece en un hoyo bajo tierra con brasas de leña y pencas de maguey, o bien en un recipiente metálico.
} 
considerados pela população como o fortalecimento do sistema imunológico. Estabelece-se uma relação entre o quente e o maior rendimento das "defesas" no corpo, de modo que durante a pandemia "grossa" ou alta consistência do caldo é preferida em lipídios acompanhados de leguminosas, em vez de lipídios saturados como chicharrón de porco, birrias, etc. Embora o consumo de alimentos quentes faça parte dos valores e símbolos do corpo e da alimentação no México, neste documento também o levantamos como parte da ação social que faz parte dos eventos cotidianos, que ressurgem em um contexto de crise e saúde e incerteza econômica. Este exame é feito por meio da colaboração interdisciplinar do ponto de vista da nutrição e da antropologia, o que nos permite apresentar um cenário mais amplo em relação às práticas alimentares das pessoas. Para isso, fomos ao estudo de caso de um paciente recuperado do COVID-19, bem como a ethnografia do consumo de alimentos em um mercado em área urbana popular.

Palavras-chave: Covid-19; Alimentos; Caldos

\section{ABSTRACT}

The objective of this article is to analyze food practices during the Covid-19 pandemic in a province in mexico's central-West. In this context food consumption has been distinguished by the predilection of broths and stews that are considered by the population as strengthening the immune system. A relationship is established between the hot and the higher yield of the "defenses" in the body, so that during the pandemic "thick" or high broth consistency is preferred in lipids accompanied by legumes, rather than saturated lipids such as pork chicharrón, birrias, etc. While the consumption of hot foods is part of the values and symbols on the body and food in Mexico, in this document we also raise it as part of the social action that is part of daily events, which resurface in a context of crisis and health and economic uncertainty. This examination is done through interdisciplinary collaboration from the point of view of nutrition and anthropology, which allow us to present a broader scenario in relation to people's food practices. To do this, we went to the case study of a patient recovered from COVID-19, as well as the ethnography of food consumption in a market in a popular urban area.

Keywords: Covid-19; Food;

\section{La Comida Popular en México}

La transición en las formas de alimentación en México ha variado de manera importante desde mediados del siglo XIX, momento en que el choque entre las clases sociales provenientes de Europa, élites nacionales y la población rural e indígena, se manifestó de manera más clara en las preferencias por los alimentos. Según Pilcher, los mexicanos ya reconocían en los tamales y los moles coloniales os componentes de la cocina nacional y se dejaban ver una gran diversidad de platillos. 
Una de las pautas que se marcaban en los recetarios familiares, eran las diversas cocinas regionales que proliferaban gracias a la lealtad que se tenía hacia las "patrias chicas", de manera que los platillos, eran una especie de bandera identitaria en un país que apenas experimentaba sus albores como nación. No obstante, paralelamente, las influencias del discurso cientificista relativo a la higiene, el progreso y la alimentación al estilo europeo, eran una contraparte importante a partir de la que se promovió una asociación del consumo de maíz con los indígenas, la pobreza e ignorancia, de manera que, se exaltaba el consumo del trigo como un sinónimo de civilización. ${ }^{1}$

Pese a este discurso peyorativo hacia la alimentación indígena, en la creciente Ciudad de México, se dejaba ver una variedad de alimentos por las calles que daban cuenta de la diversidad y dinamismo de su consumo.

La gente común, con viviendas deplorables o inexistentes, comía en las calles. La cocina prehispánica de metate y comal, casi inmutable desde la conquista, proporcionaba una comida barata y deliciosa para ayudar a soportar la carga de la existencia urbana. Una mujer podía poner un brasero en cualquier esquina, y en cuanto tenía fuego encendido, hacía un buen negocio vendiéndoles enchiladas a los transeúntes. (Pilcher, 88)

Una vez iniciado el siglo XX, particularmente después de 1910, las fuerzas revolucionarias significaron un contrapeso respecto de la visión desarrollista y eurocentrista que se acuñó durante el Porfiriato ${ }^{4}$, de manera que la inclusión de los campesinos e indígenas en el proyecto nacional contribuyeron a una cierta reivindicación de los valores de estas poblaciones. No obstante, después de tres décadas, el ideal del modelo cultural europeo persistía con otros matices que insistían en incorporar en las poblaciones campesinas nuevos hábitos de higiene y alimentación, así el debate acerca del consumo de maíz y trigo seguía en apogeo. Según Pilcher, en las escuelas se sugería a las mujeres la elaboración de pan, en

\footnotetext{
${ }^{4}$ El porfiriato es un periodo que se caracterizó por el progreso material y la llegada de capital extranjero a México. Se logró un clima de pacificación del país gracias al uso de la fuerza, la persecución y la represión de cualquier forma de descontento social, lo que le daba a este periodo de gobierno ciertas las características de una dictadura. Se produjeron tensiones entre la oligarquía porfirista (latifundistas, extranjeros, industriales) -privilegiada por Díaz- y las masas trabajadoras, el campesinado y los indígenas, quienes fueron particularmente maltratadas y explotadas durante el régimen.
} 
lugar de tortilla; sin embargo, las poblaciones se mostraron reacias a seguir este modelo de alimentación.

Fue hasta la década de los cuarenta, cuando se reconocieron los atributos de la dieta indígena y campesina, ya que, durante esta época, el gobierno buscaba mejorar las condiciones nutricionales de la población. Para ello se estudiaron las técnicas de preparación de alimentos, así como los efectos de la dieta tradicional que mostraron que la alimentación indígena proporcionaba suficientes elementos para desarrollarse ya que contiene hidratos de carbono, proteína en el maíz y el frijol, vitaminas y minerales. Así, en el transcurso de los años, el discurso oficial cambió, mientras en la década de 1940 esta alimentación aparecía como un paradigma contra el desarrollo, hacia 1960 se reconsideró el planteamiento de su prevalencia en relación a la determinación económica de las poblaciones, eventualmente, ello dio paso a la incorporación de las ideas sobre el valor simbólico de los alimentos. ${ }^{2}$

Posteriormente, como parte de la transformación industrial en México sucedida entre la década de 1940 a 1970, la disponibilidad de alimentos procesados se incrementó de manera notable en las principales ciudades del país. La alimentación asociada a lo indígena pasó de ser un esquema basado en la agricultura de subsistencia a una alimentación variada en la que intervienen otros factores como la mercadotecnia y la alta disponibilidad de alimentos industriales. ${ }^{2}$

Asimismo, la alta migración de población rural e indígena a las principales ciudades del país contribuiría a la mayor disponibilidad de alimentos y recetas con este origen, de forma que en las ciudades la persistencia de ingredientes originarios, así como sus valoraciones se mantuvieron asociadas a las nuevas pautas de consumo urbano.

\section{Lo caliente como atributo significativo}

Como bien señala Sidney Mintz, comer no es una mera actividad bilógica, sino también una actividad vibrantemente cultural. Es una base para relacionar el mundo cultural con el mundo de las ideas, y en tanto, una base para relacionarse con el resto del mundo. (3) Plantea que no se sabe planamente las formas precisas 
cómo la gente pasa de lo tradicional a lo nuevo o lo moderno, de tal forma que se cambia de la comida tradicional a la industrializada sin entenderse los cambios que estos procesos implican. Pero "lo que parece probable es que esos cambios repiten o reinterpretan secuencias previas similares, las cuales a medida que suceden recapitulan etapas históricas bastante regulares o recurrentes por las cuales fuerzas externas dominaron el consumo". ${ }^{3}$

En el caso de la significación acerca de lo caliente en los alimentos, es necesario remitirnos al proceso de transmisión generacional de valores culinarios que se hace a través de recetarios familiares o de la tradición oral. Cuando se habla de la tradición culinaria:

\begin{abstract}
Nos referimos a algo que ha sido y que sigue siendo heredado o transmitido como un sistema simbólico para dar cuenta de la realidad, a guisa de un saber apropiado que funciona como marca de identidad, como puede serlo algo que ha sido regenerado por esa apropiación y que funciona como mecanismo hermenéutico: la cocina, como tradición oral, es un sistema simbólico que interpreta el mundo cultural circundante y funciona como un lenguaje que posibilita una variada tipología de procesos de comunicación; la cocina es, en efecto, un centro de comunicación. ${ }^{4}$
\end{abstract}

Según Pérez, un elemento nuclear en el concepto de tradición es su carácter de acontecimiento que viene del pasado, que lo dota de prestigio adquirido a partir de la severidad de las tradiciones orales a las cuales se les otorga autoridad dentro de la cultura.

De manera que los recetarios, deben entenderse más allá de un catálogo de gustos variados, como parte de comportamientos sociales que se recrean en comunidad y que se vuelven una expresión, de la manera como se percibe el mundo y la trasmisión de códigos que se concretan en la comida. ${ }^{5}$

En México, la asociación de los alimentos con las temperaturas proviene de una serie de nociones asociadas con la cosmogonía indígena y que aún perduran en varias regiones. Uno de los estudios pioneros que constata lo anterior, fue el de Alfredo López Austin (2004), quien señala que a partir de los años treinta las investigaciones sobre poblaciones mexicanas indígenas y mestizas descubrieron la clasificación entre dos extremos opuestos, de alimentos, enfermedades, medicinas y tipos de personas. Esta polaridad tiene como base la distinción entre naturaleza fría y naturaleza caliente de los hombres y sus estados patológicos. ${ }^{6}$ 
Según este autor, ante un estado de desequilibrio patológico o de riesgo, se procura restablecer la normalidad por medio de la ingestión o de la aplicación de productos de naturaleza contraria al mal. ${ }^{6}$

Posteriormente, en 1953, Foster hizo una réplica al trabajo de López Austin, arguyendo que las concepciones sobre lo frío y lo caliente derivaban de la teoría europea de los humores que establecía cuatro calidades básicas: calor, frío, sequedad y humedad, que a su vez caracterizaban los elementos aire, tierra, fuego y agua. Sin embargo, según López, Foster trató de encontrar antecedentes de una división dual en España, la cual sólo operaba con lo frio y lo caliente. Para este último era claro que la teoría de los humores había llegado a América, sin embargo, quedaba pendiente la pregunta acerca de la pérdida de los criterios acerca de la sequedad y la humedad, para ser arraigados el del calor y frío. ${ }^{6}$

En respuesta a Foster, López propuso la posibilidad de que la polaridad tuviera un origen americano que enlistó en esto puntos: 1) la polaridad frío-calor no se reduce al campo de la salud, la enfermedad y la medicina, si no que comprende todo un cosmos. b) se ha mantenido una correspondencia entre cielo-fuego, machocaliente, por un lado, y por otro, tierra-agua-hembra-frío, por el otro. 2) Existe una imbricación de los poderes del cosmos con la enfermedad. 3) existen menciones muy antiguas del sistema. 4) imposibilidad de degeneración en los términos propuestos 5) antigua alusión específica a la polaridad 6) referencias al sistema. (6)

Entonces, la enfermedad puede ser causada por el exceso de calor o frío en un área particular del cuerpo y para curarlo hay que aplicar algo que absorba la temperatura. Por ejemplo, estudios acerca de medicina tradicional mexicana señalaban que las enfermedades respiratorias como los resfriados, neumonías y bronquitis son causadas por aires fríos. Una persona se vuelve vulnerable a un aire cuando se mueve de un lugar tibio a uno frío, de igual forma, una persona que acaba de comer se vuelve vulnerable a los aires. También se dice que los aires causan parálisis, convulsiones, llagas inflamaciones en la piel y los ojos, y que se originan en hormigueros, fondos de ríos, lugares húmedos donde vive el diablo. ${ }^{7}$

Estudios más recientes, encuentran una persistencia en ciertos señalamientos hechos por las investigaciones señaladas: a) el hecho de que la clasificación dentro de este sistema frío-caliente abarca toda la naturaleza, 
incluyendo las enfermedades. De esto se deriva un sistema terapéutico que emplea a los contrarios con fines preventivos o curativos ya sea con aplicación de paños fríos o calientes, pero sobre todo mediante el uso de la flora medicinal, clasificada de manera semejante. ${ }^{8}$

Según Vargas, lo que se busca mediante la interacción de lo frío y lo caliente es el equilibrio de cada persona, no solamente interno, sino en relación con el universo en el contexto de una cultura. En ese sentido, el equilibrio se hace manifiesto en el cuerpo, entendiendo que este adquiere un carácter de multiplicidad: es a la vez sólido, elusivo, ilusorio, concreto, metafórico. Un sitio, un instrumento, un entorno. ${ }^{9}$

Parte de este equilibrio, radica en estar a salvo de la enfermedad, lo cual tiene sentidos divergentes. En la teoría sociológica se han integrado los conceptos de enfermedad (disease), haciendo referencia al modelo biológico, como la alteración o disfunción de órganos o sistemas. El padecimiento (illness) incorpora la experiencia y la percepción. Malestar (sickness) hace referencia al producto de la relación de los anteriores (malestar igual a enfermedad más padecimiento), Kleiman en Moreno, 2007)

Concebir tanto a la enfermedad y al padecimiento como procesos socialmente construidos permite comprender de manera más amplia esta relación. De manera que la experiencia en torno a estos, resulta vital cuando se reflexiona acerca de las prácticas relativas a la salud. Entre ellas, se encuentran la alimentación y los sentidos atribuidos a ello, -constituidos tanto de manera individual y colectiva. En este último sentido, nos encontramos ante la complejidad de desentrañar la concepción popular y científica de la salud y enfermedad.

Devillard (1989), destaca los señalamientos hechos por Herzlich, quien hizo referencia acerca del discurso profano sobre la salud y la enfermedad como algo que fundamentalmente debe verse referente a las relaciones entre el individuo y la sociedad en el que aquellas funcionan como «significante» de éstas. De acuerdo con el autor, esto es observado en las representaciones en torno a la etiología pensada en relaciones comúnmente concebidas en términos conflictivos de una agresión padecida por el influjo de agentes maléficos, procedentes de las propias 
sociedades, así como en las consecuencias de la enfermedad y en la construcción de la idea de persona. (5, p.85)

Laplantine (1999), expresa una intención de estudiar la enfermedad y curación interiormente examinadas, fantaseadas, representadas, que él traduce como vitalmente experimentadas. Este autor, indica que la enfermedad (illness) se experimenta subjetivamente y desde la práctica médica se subordina la forma en que es científicamente objetivada y observada (desease).

Por ello, Involucrar el orden simbólico en el estudio de los procesos de salud enfermedad es una postura que se mantiene vigente. Como indica Castro, las concepciones que la sociedad se forma acerca de los enfermos se de forma que estas orientan, organizan y legitimizan las relaciones sociales, así como en cierta medida, 'producen' la 'realidad' de los enfermos (Herzlich y Pierret, 1985: 146 en Castro, 2002) ${ }^{5}$.

Castro retoma de Herzlich la idea de que el lenguaje de la enfermedad no es el lenguaje del cuerpo. Desde este punto de vista los pacientes, a diferencia de los médicos, tienden a localizar, en la medida de los posible, las funciones y sus debilidades. (op. cit,2002 ) Ahí esta implícito el lenguaje de la salud y la enfermedad de forma que las imágenes de la sociedad y sus restricciones, como las perciben los individuos, se pueden acceder a través del lenguaje de salud y enfermedad.

Para nosotros, parte de estos lenguajes son las nociones alrededor de las recetas y sus atribuciones sanadoras. Ahora, si bien desde el punto de vista médico y de la nutrición no hay evidencia de que el consumo de caldos contribuya de manera franca al fortalecimiento inmunológico, desde hace décadas, algunos estudios han documentado la ingesta de caldos de huesos y pollo como parte de las prácticas sociales recurrentes ante el riesgo de enfermedad. Uno de los primeros estudios realizados con los caldos de hueso con y sin verduras fue publicado en la revista Archives of Disease in Childhood por los investigadores Elsie

\footnotetext{
${ }^{5}$ Castro reflexiona acerca de la hipótesis principal de Herzlich y Pierret que concibe la figura de la persona enferma como históricamente evolucionada. Por ejemplo, retoma el ejemplo: cuando las plagas eran la forma dominante de enfermedad, el concepto de persona enferma no existía con la claridad que existe actualmente, debido a que la colectividad entera ya fuera la ciudad o todo el país- y no solamente los individuos aislados, era atacada y a menudo eliminada. Para estos autores, el concepto más individualista de la persona enferma ha surgido de manera gradual, en la medida en que la experiencia de los individuos sobre el mundo también se ha individualizado.
} 
Widdwson y Robert MacCance en 1934. Ellos concluyeron que el caldo de huesos era muy insuficiente con respecto al aporte de nutrientes, pero cuando se le adicionaba verdura, nutrimentos como potasio, calcio, magnesio y hierro se podían encontrar en este platillo. ${ }^{10}$

Posteriormnte, Marvin A. Sackner (1978) comparó la velocidad del moco nasal al ingerir agua caliente, agua fría y caldo de pollo. Los resultados que obtuvieron fueron que la sopa o caldo de pollo caliente actúa a través del aroma sobre la mucosa nasal o a través de la faringe, o mediante un mecanismo relacionado con el sabor. En este mecanismo, parece intervenir una sustancia adicional para aumentar la velocidad del moco nasal (6,9 a 9,2 mm por minuto) a comparación del agua caliente $(6,2$ a $8,4 \mathrm{~mm}$ por minuto) y agua fría (7,3 a 5,3 mm por minuto), 5 minutos después de beber el primer sorbo. Este estudio propone que el caldo de pollo,- al mostrar un aumento de la velocidad del moco nasal-, debería ser beneficioso en la rinitis aguda, ya que el tiempo de contacto de un patógeno en la mucosa nasal se acortaría, minimizando así su penetración y multiplicación. Respecto a la diferencia entre la ingesta de líquidos calientes y los fríos, se recomiendó la de líquidos calientes en pacientes con infecciones del tracto respiratorio superior, ya que aumenta transitoriamente la velocidad del moco nasal por la inhalación nasal de vapor de agua. ${ }^{11}$

Posteriormente, un artículo publicado en 1980, llamado "Therapeutic Efficacy of Chicken Soup" , hizo una profunda exploración de los estudios y recomendaciones importantes respecto al tema. Desde el siglo XII, el filósofo y médico Moisés Maimónides, hacía referencia sobre los beneficios de la sopa o caldo de pollo y otras aves para el tratamiento de enfermedades como: inicios de lepra, aumento de peso para tratar adelgazamiento, convalecencia para enfermedades generales, fiebre crónica, mucosa nasal, neumonía y asma; así como otras aves como codorniz, paloma, perdiz, gallina y pato para tratar estreñimiento, mejora de la memoria e intelecto, potencia sexual, cálculos renales y aumento de flujo de la orina,respectivamente. Así fue como concluyó, que ciertas carnes tenían una fuerte influencia con la mejoría de ciertas patologías en el cuerpo humano. ${ }^{12}$

En octubre del 2000, la revista CHEST publicó un artículo llamado " Chicken soup inhibitsneutrophil chemotaxis in vitro", (Barbara O. Rennard, Ronald F. Ertl y 
Gail L. Gossman), 2000 .Por medio de un método llamado "Modificación de la cámara oculta de Bayden", demostraron que la sopa de pollo lleva a cabo una inhibición estadísticamente significativa de la quimiotaxis de neutrófilos ${ }^{6}$, en respuesta a los estímulos quimiotácticos estándar, los cuales, están asociados con la generación de resfriados causantes de tos y esputo de un conjunto diverso de infecciones. Por lo tanto, los hallazgos de tal estudio si admiten que la sopa de pollo tiene efectos antiinflamatorios, mejoramiento en el tránsito respiratorio y aceleración en el aclaramiento de la mucosa. ${ }^{13}$

En contraste con los resultados obtenidos en el caldo de pollo, un estudio realizado en Reino Unido (Monro y R. Leon, 2013) planteó la hipótesis de que el caldo de huesos podría conllevar un riesgo de contaminación con plomo, basado en un pequeño estudio que midió las concentraciones de plomo en diferentes tipos de caldo de pollo orgánico.

Esta investigación encontró que el caldo hecho de piel y cartílago (extraído del hueso una vez que el pollo se había cocinado con los huesos) y el caldo de hueso de pollo, tenían concentraciones marcadamente altas de plomo, de 9.5 y 7.01 $\mu \mathrm{g} L-1$, respectivamente (en comparación con un valor de control para el agua del grifo de 0,89 $\mu \mathrm{g} L-1$ ). ${ }^{14}$ Este estudio alertó a los médicos y nutriólogos para considerar las recomendaciones de este tipo de caldos para los pacientes, ya que el plomo presente de manera significativa en este alimento puede ser transportado a los huesos afectando su crecimiento, desarrollo y reabsorción ósea, así como afectar al sistema circulatorio y en tejidos blandos. Luego, en el 2016, artículo publicado por la revista TIME, titulado "Science cant't explain why everyone in drinking Bone Broth", habla del trabajo que han hecho algunos investigadores sobre el "caldo de huesos" respecto a su atribución del colágeno y aparente aporte nutrimental. Concluyó que el colágeno no contiene una cantidad de aminoácidos significativa y cuando se absorben en el organismo no alcanza a realizar el crecimiento óseo ni los demás beneficios que se le atribuyen. Por lo tanto, la ingestión de colágeno no se convierte en colágeno dentro o entre los huesos. ${ }^{15} \mathrm{De}$ acurdo con lo anterior, a diferencia de los resultados con hasta ahora poca evidencia

6 Proceso inflamatorio que se da por la quimiotaxis (estímulos bacterianos o de cualquier sustancia difusible) hacia los neutrófilos, al liberarse interleucinas en donde hay daño tisular. 
científica del "caldo de huesos", el caldo de pollo con verduras ha mostrado beneficios medicinales para la ciencia.

Actualmente, ha resutgido este tema a propóstito de los habitos alimenticios de la población durante la pandemia. Al respecto, la revista CHEST publicó en mayo del 2020 un artículo llamado "Chicken Soup in the Time of COVID" ( Percy, 2016) en el que se propone la sopa de pollo como un apoyo psicosocial más allá de su valor medicinal potencial que ayuda a hacer frente a las amenazas personales y sociales muy reales y las ansiedades asociadas, por encontrar un método alternativo al tratamiento psico-alimenticio del COVID 19. ${ }^{16}$

Entonces, vale la pena preguntarse ¿Cómo ciertos significados relativos a las propiedades culturales atribuidas a la comida se incorporan en contextos, - como la pandemia Covid-19-, en los que la salud se ve en riesgo? y ¿Cómo se asimila el sentido del bienestar y la salud a partir del consumo de alimentos específicos? A partir de estos cuestionamientos se emprendió un estudio exploratorio para conocer la modificación de hábitos alimenticios en la población durante la pandemia ocasionada por el COVID-19.

\section{Entorno social del mercado durante la pandemia COVID-19 en la provincia mexicana.}

El mercado en el que se realizó la breve etnografía se encuentra localizado en una de las zonas urbanas populares de la ciudad de Aguascalientes ${ }^{7}$, México (Ver fotografías 1 y 2). Durante tres semanas se realizó observación no participante acerca del consumo y compras para la canasta básica durante el periodo de contingencia. Primero, se identificaron a las y los comensales recurrentes a partir de lo cual se tipificó la población que constantemente transitaba y sus dinámicas de consumo de alimentos. Posteriormente, se llevaron a cabo conversaciones con

7 El estado de Aguascalientes es parte de la región bajío-occidente y se avecina con Zacatecas y Jalisco. La población del estado asciende a 1,316, 032 habitantes y su principal actividad económica es la industria manufacturera asociada al campo automotriz.

La mayor parte del año presenta un clima seco por lo cual la producción agrícola es limitada, en comparación con otras regiones de México. En el estado se producen Chiles: las variedades más utilizadas son el tipo ancho, verdeño, criollo, flor de pabellón y pasilla, Utilizados para la preparación de moles, caldos, sopas y salsas, entre otros. Asimismo, se cultiva frijol, nopal, papa y vid. La guayaba es uno de las producciones más voluminosas en el estado con la cual se elaboran dulces, licores, salsas y otros productos alimenticios. 
consumidores, se realizaron entrevistas a comerciantes de frutas y verduras, propietarios de fondas y cocinas económicas. En segundo lugar, esto permitió explorar las modificaciones en la dieta que respondían a la preocupación por enfermar y las valoraciones que la gente atribuye a los alimentos y su preparación.

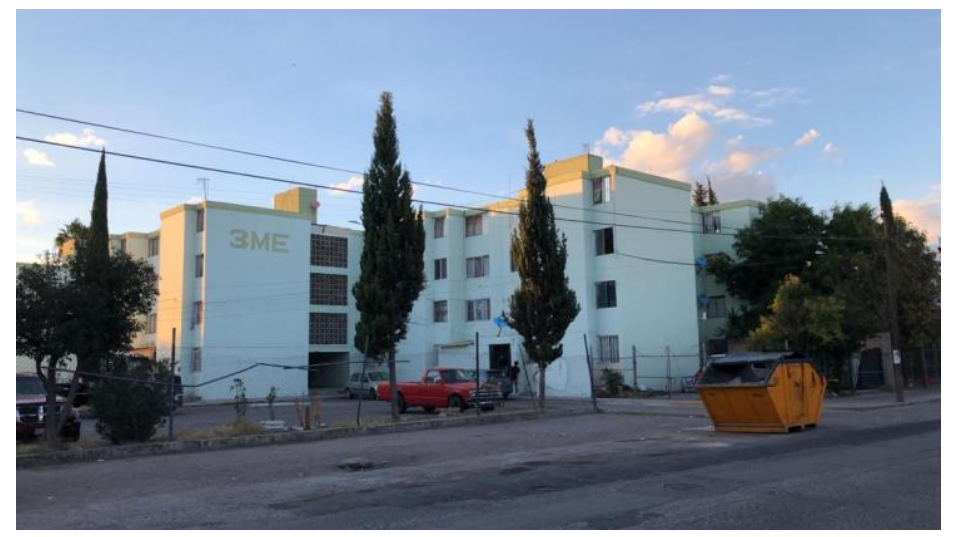

Fotografía 1: Edificios y viviendas a la periferia del mercado de estudio

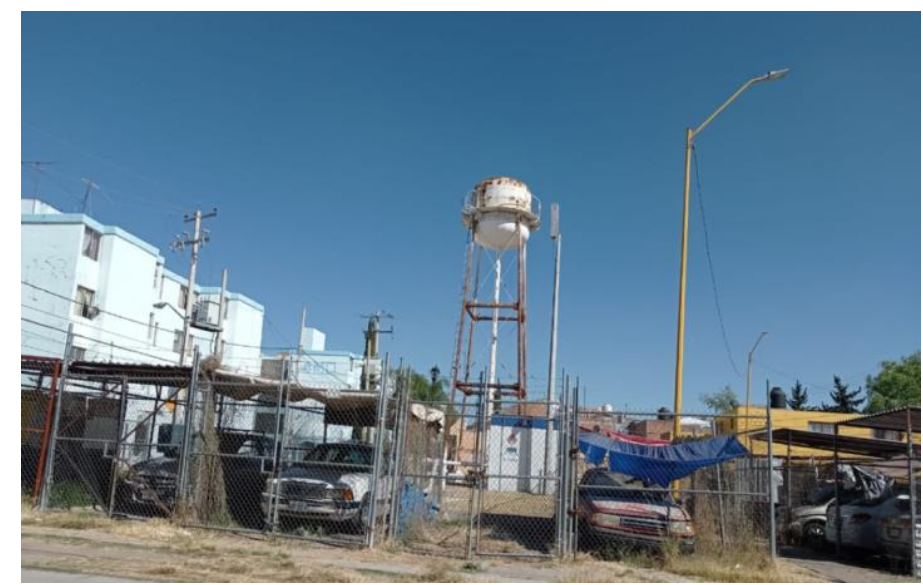

Fotografía 2: Contexto de la periferia del mercado de estudio

En el país, el primer caso de COVID-19 fue reportado la tercera semana de febrero y en el estado se confirmó el primer caso a mediados del mes de marzo. En la etapa intermedia de la pandemia, hasta la primera semana del mes de julio, los casos positivos a nivel nacional ascendieron a 286, 248 y un total de $30,639^{8}$.

8 Gobierno de México. Comunicado Técnico Diario COVID-19, México. Disponible en https://www.gob.mx/cms/uploads/attachment/file/561545/Comunicado_Tecnico_Diario_COVID19_2020.07.05.pdf 
defunciones. A finales del mes de noviembre se reportan 1,078,594 casos positivos y 104,242 defunciones. $^{9}$

En las mismas fechas, en el mes de julio se reportaron en el estado de Aguascalientes 336 casos confirmados y 166 defunciones ${ }^{10}$. En noviembre los casos positivos de COVID-19 ascendieron a 12276 y 1240 decesos ${ }^{11}$. Los gobiernos federales y estatales han enfrentado una serie de críticas por su actuación ante la pandemia. En el caso particular de la entidad, en cuatro meses se incrementaron exponencialmente el número de contagios y defunciones debido a la constante movilidad de la población, reuniones sociales y poca eficiencia de los protocolos de seguridad e higiene entre la población.

La falta de infraestructura, personal e insumos hospitalarios, pruebas para el diagnóstico y el miedo de la gente se agudizan por problemas como la pobreza, los altos índices de empleo informal y la crisis económica. Desde el inicio de la pandemia, el gobierno federal optó por una estrategia de promoción de "sana distancia" y lavado de manos. Sin embargo, la larga duración de la pandemia ha hecho inviable el aislamiento para gran parte de la población. por ejemplo, a finales del mes de abril, se reportaba hasta casi un $50 \%$ de aumento en la movilidad de las personas en el estado. ${ }^{12}$ Así, En esas circunstancias es posible encontrar espacios públicos, como los mercados, con una alta afluencia de personas que van a trabajar para obtener un ingreso diario y en busca de alimentos y comida preparada.

El mercado donde se realizó el registro de datos es un lugar de abastecimiento para alrededor de cuatro colonias populares de la ciudad. La gente que más acude a consumir en el mercado son los vecinos de las colonias, personas de las zonas residenciales cercanas y los propios comerciantes con un sistema de

\footnotetext{
8 Gobierno de México. Comunicado Técnico Diario COVID-19, México. Disponible en https://www.gob.mx/cms/uploads/attachment/file/595411/Comunicado_Tecnico_Diario_COVID19_2020.11.26.pdf

10 Gobierno del Estado de Aguascalientes. Coronavirus en el Estado de Aguascalientes. Disponible en https://www.aguascalientes.gob.mx/coronavirus/ (consultado en julio de 2020)

${ }^{10}$ Gobierno del Estado de Aguascalientes. Coronavirus en el Estado de Aguascalientes. Disponible en https://www.aguascalientes.gob.mx/coronavirus/ (consultado en noviembre de 2020.

12 Nota de prensa. "En Aguascalientes aumenta movilidad pese a cuarentena por Covid-19" Aristegui Noticias. abr 28, 2020. Consultado el 3 de julio. Disponible en https://aristeguinoticias.com/2804/mexico/en-aguascalientes-aumenta-movilidad-pese-a-cuarentenapor-covid-19-video/
} 
trueque y/o compra. Ahí adquieren alimentos básicos, objetos personales o para el hogar por lo que es un punto fundamental de interacción social.

Cuadro 1 - Tipo de población que acude al mercado

\begin{tabular}{|l|l|l|}
\hline \multicolumn{1}{|c|}{ Género } & \multicolumn{1}{|c|}{ Edad } & \multicolumn{1}{c|}{ Ocupación } \\
\hline Niñas & $6-11$ & Estudiantes \\
\hline Niños & $6-11$ & Estudiantes. \\
\hline Mujeres & $12-16$ & Estudiantes y trabajo doméstico. \\
\hline Hombres & $14-17$ & $\begin{array}{l}\text { Estudiantes, trabajo en barberías, carpinterías, vidrierías y } \\
\text { abarrotes. }\end{array}$ \\
\hline Mujeres & $18-45$ & Amas de casa, aseo en casas particulares. \\
\hline Hombres & $18-40$ & $\begin{array}{l}\text { Comerciantes, transportistas y almacenistas en empresas } \\
\text { privadas. }\end{array}$ \\
\hline Mujeres & $55-70$ & Amas de casa, pencionadas y jubiladas \\
\hline Hombres & $55-70$ & Pencionados, jubilados y comerciantes. \\
\hline
\end{tabular}

Fuente: Elaboración propia realizada con base en datos de trabajo de campo.

El equipamiento del mercado consiste en 4 cocinas económicas, 2 loncherías ${ }^{13}, 4$ comercios de platillos preparados a base de carne (birria y derivados), 4 fruterías/verdulerías, 6 carnicerías y 3 pollerías, 3 negocios de semillas y cereales, 3 dulcerías, 3 tortillerías/venta de cacao, tiendas naturistas y un par de negocios de objetos personales y para el hogar.

Un rasgo muy importante de la población consumidora son los niños, niñas y adolescentes, ya que después de salir de las primarias y secundarias aledañas pasear adentro del mercado es parte de la vida cotidiana de las colonias, pues las familias que viven cerca los envían a comprar alimentos y otros insumos necesarios para el hogar. A pesar de las restricciones para mitigar la transmisión de virus entre la población, la vida en el mercado se ha mantenido muy activa durante la pandemia. Una referencia muy importante es la imposibilidad de mantenerse en cuarentena debido las condiciones económicas que se tienen y los aspectos de su vida diaria como el cuidado de los hijos, las personas mayores, el abastecimiento de

13 Establecimiento donde se sirven platos ligeros y refrigerios, como tortas, tacos, quesadillas, sándwiches, refrescos, jugos, etc. 
comida, e incluso, la indisposición para mantenerse en casa, ya que muchas de los casos residen en viviendas pequeñas o departamentos de interés popular en los que conviven 4 o más personas.

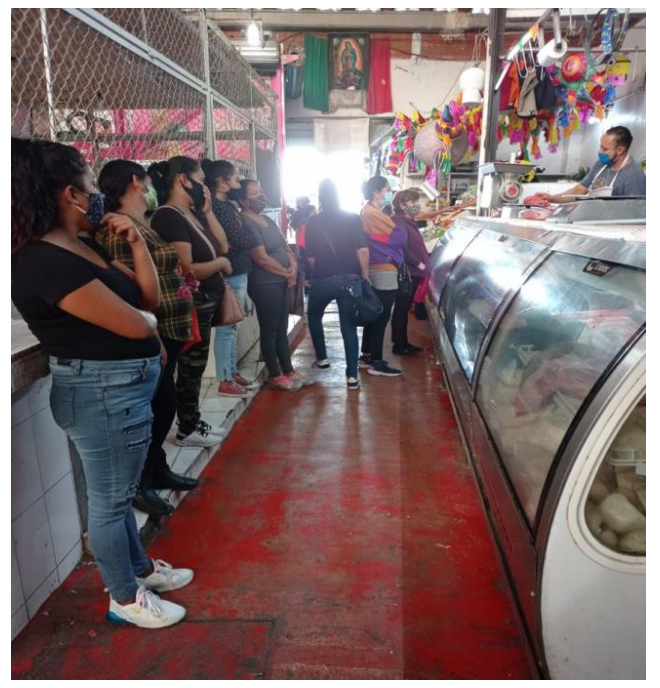

Fotografía 3: Fila de personas para la compra de alimentos frescos.

En distintos horarios, se pueden encontrar hombres, mujeres que llevan a sus hijos y jóvenes que pasan por el mercado. Buena parte de las personas que consumen alimentos preparados en ese mercado son comerciantes, transportistas, almacenistas, amas de casa, empleadas de aseo en hogares particulares, diversas personas de edad avanzada que se encuentran jubilados o pensionados y un porcentaje reducido de personas profesionistas ${ }^{14}$.

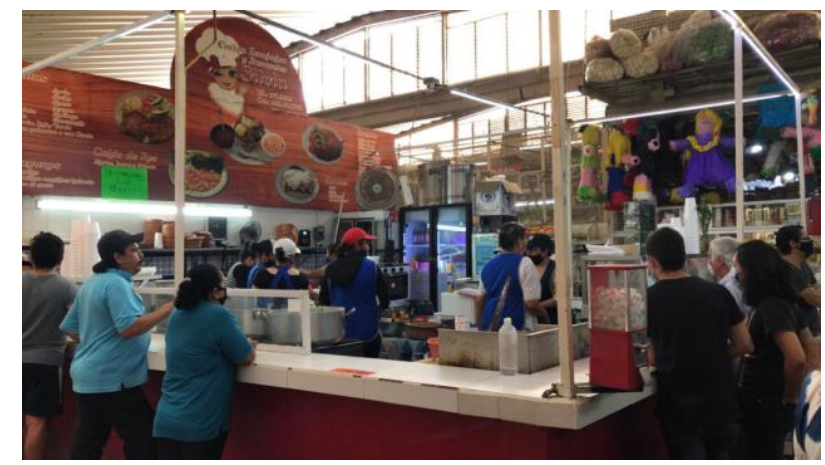

Fotografía 4: Cocina económica de estudio

${ }^{14}$ Notas de campo y entrevistas realizadas a comensales. Aguascalientes, Ags. (Junio-Julio, 2020) 
La oferta de alimentos es variada y la mayor parte de los productos son frescos. Una pequeña parte de comerciantes oferta productos cosechados y producidos por ellos mismos. Los comercios que más demanda tienen son los que funcionan como cocinas económicas, ya que se encargan de facilitar el acceso de alimentos calientes preparados el mismo día y con un tiempo de servicio muy eficiente a trabajadores de distintos rubros y gente que sale de sus empleos y quienes van de paso. El mayor volumen de venta de caldos, sopas calientes y otros alimentos preparados en las cocinas económicas sucede entre 12:00 a 15:00.

La cocina económica que registra mayor afluencia de gente es la de "Doña Silvia", donde los platillos con mayor demanda desde que inicio la Pandemia de COVID-19 en México son los caldos de res y de pollo con verdura15. Esta es la isla más grande del mercado debido a la demanda de consumo que tiene esta cocina económica, la cual se puede constatar por la cantidad de comida que se prepara al día y las filas que realizan las personas para obtener el servicio.

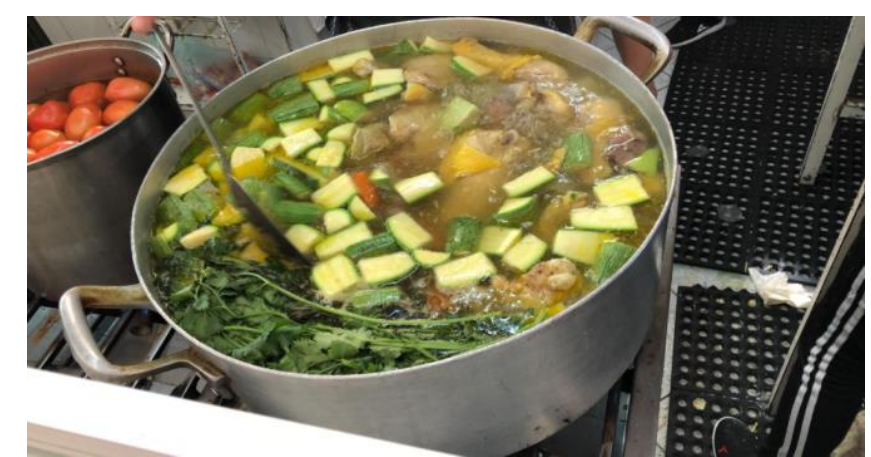

Fotografía 5: Preparación del caldo de pollo, un platillo de estudio.

\section{El consumo de caldos calientes durante la pandemia: salud / enfermedad autoatención.}

Poco a poco a gente modificó el consumo de alimentos. Optaron por alimentos frescos o "naturales" porque según ellos esto ayuda al aumento de defensas. Aunque persiste el consumo de alimentos altos en grasas, la gente trata de combinarlos con alimentos a los que les atribuyen un cometido alto de vitaminas como frutas altas en azúcar, cítricos y alimentos ricos en aceites y proteínas.

${ }^{15}$ Notas de campo y entrevistas realizadas a comensales. Aguascalientes, Ags. (Junio-Julio, 2020) 
"He comido más fruta mango, mango, aguacate. El aguacate trae aceitito y que es muy bueno para las defensas. He metido mucho pescado, la gente pide mucho los caldos"16

"Pienso que te ayuda a la sangre. Yo tomo mucho caldito de pollo porque siento que me alimenta y me siento bien. Dicen que tomando caldito se calienta y no se enferma uno, bueno eso nos dijo un doctor. El caldo es bueno por las verduras que trae" 17

En los datos recabados, se encontró una relación entre cuatro dimensiones de la vida cotidiana de las personas, que se han visto modificadas por la pandemia COVID-19. Se identificaron referencias relativas a dimensiones como 1) el miedo a la enfermedad, 2) el cuidado del cuerpo, 3)la vida cotidiana, 4)el trabajo y actividades económicas que mucha gente no puede suspender ya que depende de un ingreso diario.

Comerciantes, así como comensales de las cocinas económicas del mercado expresaron:

\footnotetext{
"Tengo miedo por lo que pueda yo llevar (a casa) sin saber...mi alimentación es muy variada, ando(trabajo) en la calle.

"Soy comerciante. Yo creo que el virus si existe, pero yo creo que siempre ha existido, y la verdad, miedo no tengo. Me siento tranquila relajada, trato de llevar una buena alimentación. Alimentar bien a mi familia, a mis hijos, a mi esposo; hacer ejercicio y mantenerme activa ${ }^{18}$
}

Durante la pandemia estas se articulan mediante un atributo significativo relativo a lo que la gente considera la buena alimentación, y particularmente, el consumo de caldos. (Ver figura 1)

16 Entrevista a propietaria de cocina económica. Junio, 2020. Ags. Mex.

17 Entrevista a comensal. Junio,2020. Ags. Mex.

18 Entrevista a mujer comerciante del mercado. Junio. 2020. Ags, Mex. 


\section{Alimentación y vida cotidiana en el contexto de la pandemia COVID-19}

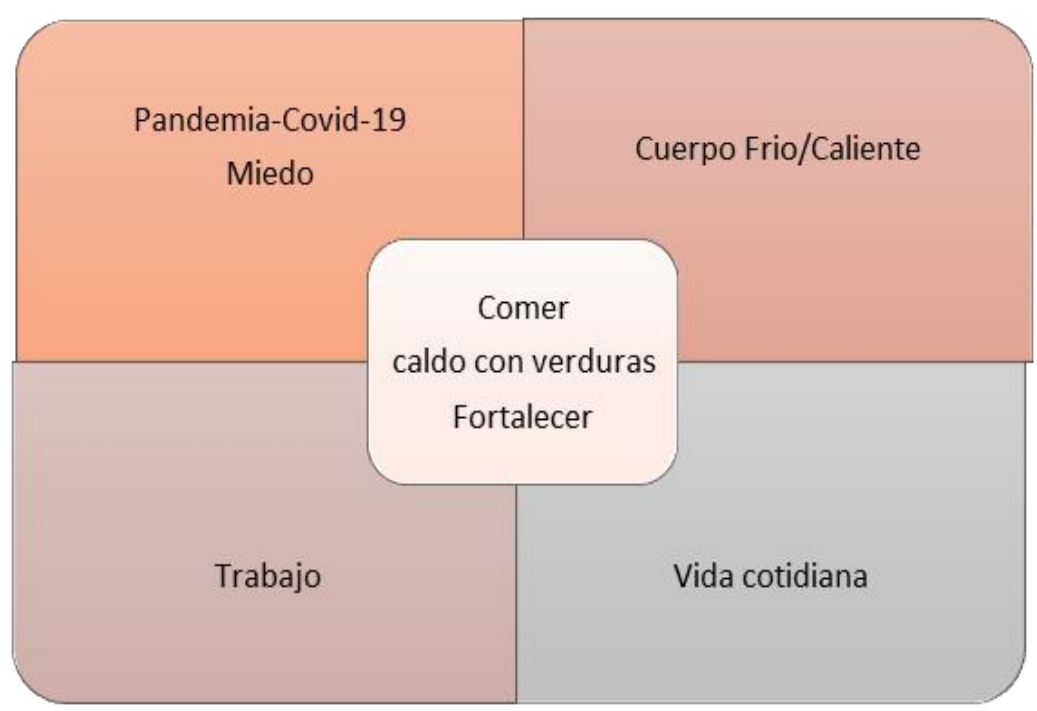

Figura 1. Elaboración propia con base en datos de trabajo de campo

Concretamente, un caso que da cuenta de la persistencia en la valoración positiva acerca del consumo de los caldos calientes como recurso para aliviar los síntomas de la enfermedad es el proceso de convalecencia de un paciente recuperado de Covid-19. Se trata de un trabajador del sistema salud, de 38 años, que se contagió en uno de los hospitales designados para la atención de pacientes infectados con el virus. Este trabajador es camillero de uno de los hospitales generales de zona del Instituto Mexicano del Seguro Social. En México es la institución de salud pública que atiende a la mayor parte de los trabajadores formales registrados por pequeñas, medianas y pequeñas empresas, así como por particulares. Este trabajador, tuvo contacto directo con varios pacientes contagiados de COVID-19 por lo cual su exposición al virus fue constante. Además de este factor, en el ámbito doméstico también convive con su esposa, quien es enfermera en la misma institución y contrajo la infección durante el mismo periodo. Ambos pasaron en casa el periodo de aislamiento junto con sus dos hijos de 9 años y 1.5 años.

Para la elaboración de caldos y alimentos calientes, el matrimonio mezcló las recetas que aprendieron de sus madres. Algunas diferían en la cantidad de verduras pero con el mismo valor relativo al efecto terapéutico. 
La familia cercana de ambos, sobre todo la madre de él, los auxiliaron recomendándoles y abasteciéndoles de ingredientes para la elaboración de caldos tradicionales calientes que les ayudaran a mejorar los síntomas de la infección.

Para adquirir los alimentos durante el aislamiento de catorce días, los padres, hermanos, hermanas, primos y sobrinos de ambas familias se organizaron para llevarles la despensa semanal. Con el fin de evitar el contacto con ellos, los alimentos eran colocados en la cochera de su casa. Esta se convirtió en la única interacción social durante su aislamiento.

La familia infectada, refirió modificar sus prácticas de vida cotidiana porque tuvieron que dejar de asistir a sus trabajos y los a lugares de recreación y obtención de víveres, entonces, enfocaron su tiempo en las prácticas culinarias familiares e interacción familiar.

La selección de alimentos por parte de la familia afectada antes de la infección, era muy variada (frutas, verduras y alimentos con alto porcentaje de grasas saturadas e hidratos de carbono simples) por ejemplo: hamburguesas, torta de carne empanizada, chicharrón, frutas, verduras, frijoles, etc. Esto se modificó de forma sustancial durante su periodo de infección, ya que las legumbres se convirtieron en un componente principal de su dieta.

De acuerdo con su experiencia, Andrevich Salas, señaló que una vez que fue diagnosticado como positivo, hizo algunas modificaciones en su alimentación:

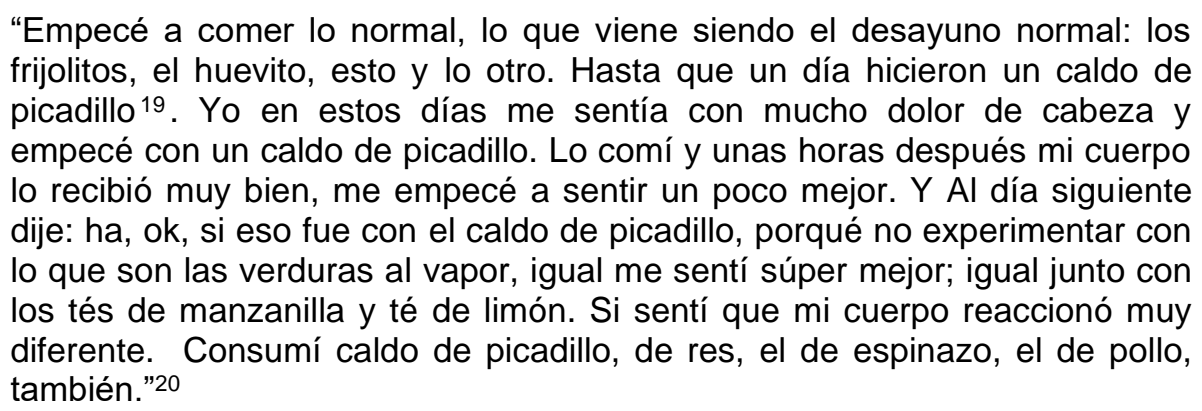

Aunque la infección ya no se presentó, la familia siguió basando su dieta en alimentos calientes como caldos de res, pollo, té de manzanilla, limón y canela, por asociarlos con mejoría de salud.

19 Guiso caldoso a base de carne de res y puerco molida al cual se añaden verduras como la zanahoria, calabaza, papa y chícharo.

20 Entrevista a paciente recuperado de Covid-19. Junio 2020. Ags. Mex. 
La preparación y consumo de caldos, ha sido alentado por su madre y abuela. Tales recetas son parte de una herencia culinaria heredada desde la cuarta generación.

"Lo de los caldos viene de la abuelita y la bisabuelita pero te soy sincero, yo el caldo que más odio es el de pollo, pero dicen que te aliviana mucho consumirlo.

Principalmente, mi abuelita que uno se ponía malo y te decía "a ver muchacho cabezón, venga para que se tome su caldito, para que se cure"

Como bien señala Pérez (2001), cuando se prepara una receta de las madres o las abuelas, se invoca la autoridad del prestigio tradicional y la aceptación de las cosas que tienen valor en una cultura. En tanto "concentra su funcionamiento social bajo "la aureola" de la autoridad generacional. ${ }^{4}$

Como se ha mencionado al principio, un punto clave es entender cómo los elementos significativos de la cultura se reorganizan para mediar la interacción entre los alimentos y las bebidas y las interacciones entre el cuerpo, la comida y en este caso las afecciones al cuerpo.

En el proceso de enfermedad y convalecencia del Covid-19, asimilarse como una "familia Covid", involucra una especie de comunidad que comparte los cuidados durante el confinamiento.

Sin embargo, estar aislado no implica estar solos, las recetas familiares aparecen y son utilizadas como un vínculo a través del cual se realizan cuidados y se actualizan como remedios para la enfermedad y en tanto, se pueden concebir como parte de una acción social como respuesta a la incertidumbre y el miedo.

En el contexto de la pandemia, tanto los remedios, como recetas adquieren una valoración relativa al autocuidado de la salud, similar al sentido de la autoatención.

Como indica Menéndez:

\footnotetext{
"La autoatención refiere a los saberes, es decir, a las representaciones y prácticas sociales que los sujetos y microgrupos utilizan para diagnosticar, explicar, atender, controlar, aliviar, soportar, curar, solucionar o prevenir los procesos que afectan su salud en términos reales o imaginarios, sin la intervención central, directa e intencional de curadores profesionales, aun cuando éstos pueden ser la referencia de la actividad de autoatención. Así, la autoatención implica decidir la autoprescripción y el uso de tratamientos de manera total o relativamente autónoma, incluso si ya han sido indicados por curadores de las distintas formas de atención" (Menéndez,2018)
} 
De acuerdo con este autor, la autoatención puede pensarse en dos niveles. El primero, abarca las formas de autoatención que se requieren para asegurar la reproducción biosocial de los sujetos y microgrupos, en especial los relativos al grupo doméstico. Estas formas se utilizan a partir de los objetivos y normas establecidos por la cultura del grupo. Ello puede incluir las actividades de preparación, distribución y consumo de alimentos; el aseo del cuerpo, el hogar y el medio ambiente inmediato; la obtención y uso del agua, la eliminación de excrementos, etc.

El segundo nivel, se refiere a los procesos de salud/enfermedad/atenciónprevención (s/e/a-p). Se hace desde la detección y en este se observa cómo los sujetos y sus microgrupos de todas las clases y sectores sociales necesitan realizar acciones inmediatas y permanentes para solucionar de manera radical o provisional los problemas de salud que los aquejan o amenazan.

Según Menendez ${ }^{21}$, no hay un corte claro entre los dos niveles. Así, el segundo hecho refiere a que lo hacen desde la detección y durante todo el lapso que dure el padecer mediante la autoatención.

Asi, podemos entender la autoatención a la infección de covid-19, como una relación salud/enfermedad/atención-prevención que se traduce en el proceso:

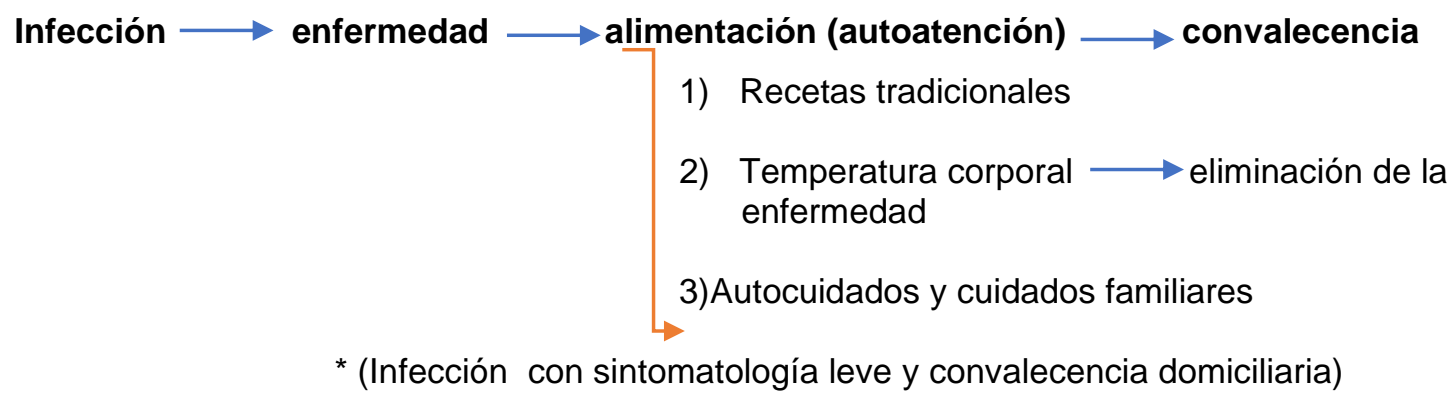

Entonces, dimensiones como las descritas en el cuadro 1 relativas al miedo, la alimentación, el trabajo y la vida cotidiana se ven mediadas por una serie de relaciones sociales entorno al cuidado de los pacientes (Cuadro 2)

\footnotetext{
${ }^{21}$ Menendez propone concebir la autoatención como una estructura permanente que los microgrupos generan en toda sociedad para atender sus padecimientos, que se caracteriza por un proceso constante de cambio, al igual que las otras formas de atención, incluida la denominada medicina tradicional La carrera del enfermo y la trayectoria de enfermedad tienen como punto de partida y llegada la autoatención. La autoatención es casi siempre la primera actividad que el sujeto y el microgrupo ejecutan respecto a los padeceres detectados.
} 
Cuadro 2 - Elementos que intervienen em el consumo de caldos família con enfermedad Convid-19

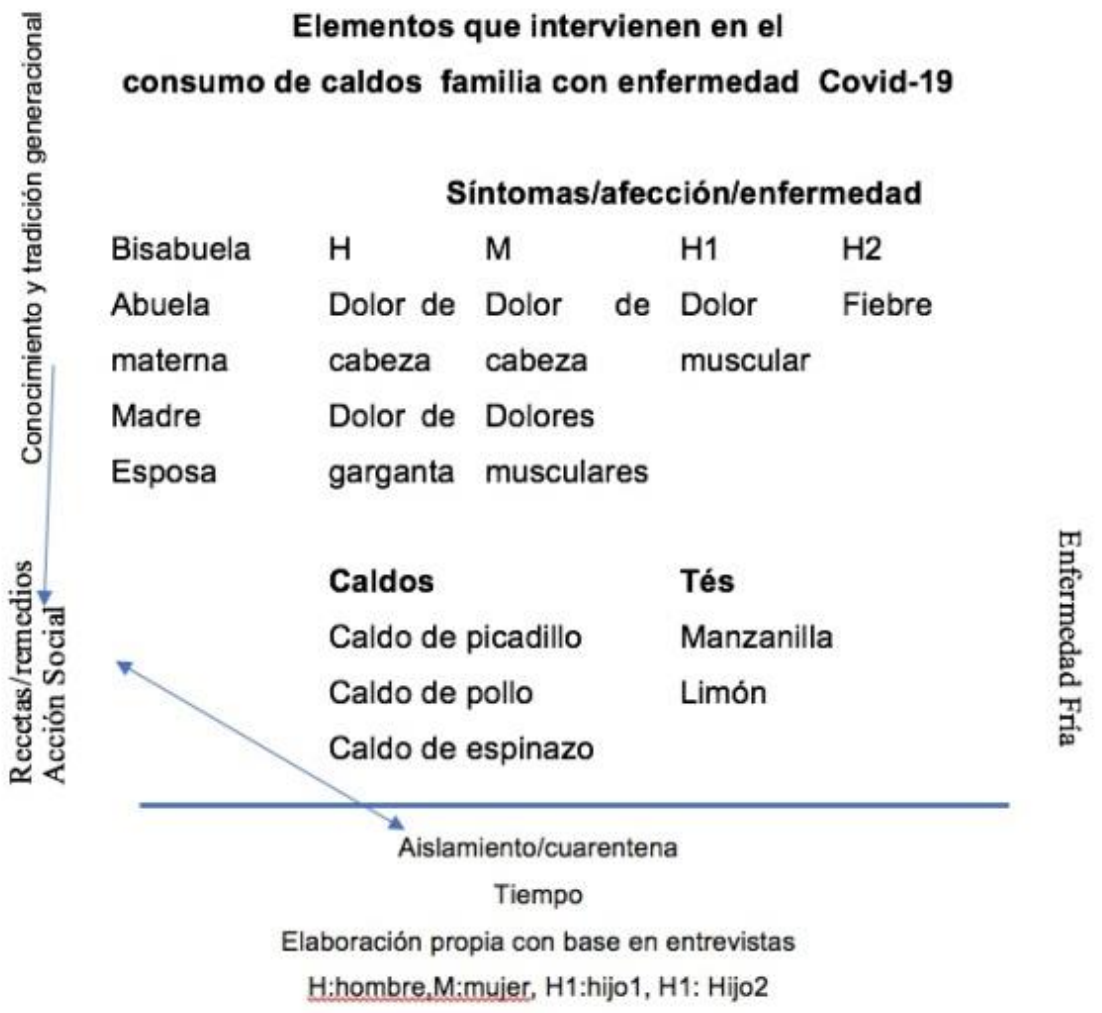

Esta se convierte en una forma de dinamizar las relaciones sociales y familiares a través del cuidado del paciente contagiado.

En este caso, la interacción entre enfermedad y alimentos se vuelve central para entender que nutrirse es también una forma de acción social y en su caso de autoatención-. Al respecto Paris Aguilar (2014), señala que en esta perspectiva de la alimentación:

Para comprender conceptualmente la dinámica del sistema es necesario ubicarnos en la perspectiva de la ecuación sujeto-objeto (sociedadnaturaleza) como unidad conceptual básica interpretativa. Ambas entidades son imposibles de comprender en ámbitos aislados o disociados, de hecho deben ser entendidos como elementos dialógicos: el sujeto actuando sobre el objeto y replanteando en esta relación su vínculo con la naturaleza y la sociedad (su entorno). El proceso de alimentación, constituye la dinámica misma con la que funciona dicho sistema. Mediante él, se pone en juego esa capacidad de autotransformación o autoinvención traducible como lo cotidiano. ${ }^{(17)}$ 
La autora se pronuncia por trascender el estado de consumo pasivo en los registros etnográficos y señala la necesidad de distinguir en las gestualidades, actitudes y operaciones alimentarias, creaciones y recreaciones de un bagaje material y cultural general específico. Habla de un sujeto capaz de gestionar y autogestionar sus hábitos de alimentación y contenidos, que a la postre son parte de la condición de la posibilidad para modificar un determinado sistema. Al respecto señala un par de principios de discusión que contribuyen a su argumento. Entonces, para Aguilar, la alimentación como acción cultural puede ser considerada como estrategia consciente de subsistencia en donde el sujeto individual y colectivo inventa el cotidiano como espacio de creatividad. (Aguilar, 2014).

Señala dos principios de discusión que contribuyen a la reflexión de su argumento:

a. En tanto hecho cultural, las prácticas de la alimentación humana presentan condiciones materiales diferenciadas y formas específicas de configuración de acuerdo con las necesidades de cada grupo, sus condiciones culturales, históricas y medioambientales concretas, conformándose así un sistema de alimentación particular con una dinámica procesual propia, susceptible de ser reconocido y comprendido con y desde distintas dimensiones y perspectivas disciplinarias.

b. Dicho sistema es dinámico y sufre alteraciones objetivas o subjetivas propias de sus condiciones, contextos y naturaleza, de corto, mediano y largo plazo. Estas alteraciones sistémico-procesuales pueden: 1) ampliar la base de sustentación del sistema (diversificar) o 2) eliminar partes o la totalidad del mismo, por medio de la sustitución de elementos (restringir). Esta cualidad ambigua establece las condiciones en las que el sujeto social y colectivo se apropia y desarrolla sus prácticas cotidianas en relación con la alimentación como práctica social, expresándose, por ejemplo, en un estado nutricio particular.

En el caso que analizamos, particularmente nos interesa el segundo punto señalado por la autora, que nos permite ver el consumo de caldos calientes como 
un hecho dinámico, que puede ser concebido como una acción en el contexto de la pandemia en el que se incorporan elementos tradicionales, colectivos e individuales.

La cotidianidad se ve interpelada por las afecciones o enfermedades, de tal forma que las y los sujetos mediante el consumo de alimentos intervienen esta realidad.

Entonces, como señala Turner (1989) una persona toma posesión de una afección, transformándola en una enfermedad significativa. Sin embargo, los seres humanos no son simples recipientes de procesos corporales, sino que actúan en el nivel de la fisiología y la biología. Se tienen afecciones pero también la producen desde el momento en que una afección se vuelve una práctica social. ${ }^{9}$

\begin{abstract}
"Procuramos comer los caldos en la comida y cena. En la mañana rompíamos la dieta, que unos huevitos rancheros, que esto y otro. Los tés los consumía, uno por la mañana, uno por la tarde y uno antes de dormir. Sentía que en la mañana un tecito de manzanilla si te abría más las vías respiratorias, muy muy bien. Creo que tanto los tés como los caldos me ayudaron para la desinflamación, que como tal no duele, solo sientes irritado y con lo caliente se o calma la molestia de la garganta. Por los nutrientes que te brinda el caldo y las verduras y principalmente lo caliente porque creo que va deshaciendo el virus o la bacteria que tenemos adentro"22.
\end{abstract}

Además de las afecciones biológicas y síntomas causados por el covid-19, en la dimensión social la caracterización del padecimiento se distingue por una intervención del conocimiento y valoraciones tradicional acerca de los alimentos y cómo estos pueden modificar de forma dinámica la condición de los sujetos.

Intervienen los conocimientos y autoridades generacionales, así como una serie de actualizaciones significativas que emergen en el contexto de esta pandemia. En la alimentación se expresan una serie de relaciones extensas que establecen sus miembros entre sí, y que no siempre requiere de estar juntos. "Se basa en la capacidad de ejercer las jerarquías, de reconocer las necesidades propias y las de aquellos con quienes se convive; de utilizar los recursos materiales, sociales e incluso los personales" 18

${ }^{22}$ Entrevista a paciente recuperado de Covid-19. Junio 2020. Ags. Mex. 


\section{Comentarios finales}

La alimentación es un hecho cultural que puede ser analizado como una acción social que da repuesta a ciertos aspectos de los contextos de crisis como es la pandemia covid-19. Un aspecto interesante es que parte del miedo al virus se ha atenuado con el consumo de caldos calientes con verduras, de tal forma que esta práctica media entre las dimensiones de su vida cotidiana. Las emociones derivadas de la pandemia COVID-19 derivan en una serie de relaciones que dan cuenta del proceso salud/enfermedad/atención-prevención. Resulta interesante observar cómo la ingesta de alimentos en zonas urbanas populares se orienta por valores tradicionales de la comida para enfrentar los temores acerca de la enfermedad.

Este consumo recupera valores transmitidos generacionalmente, que adquieren un dinamismo en el contexto de la emergencia sanitaria. La transmisión de recetas con valoraciones positivas con relación a lo caliente devela que las relaciones de parentesco son una manifestación acerca de cómo las experiencias, valores y significados pueden fusionarse para resignificar prácticas de cuidado al cuerpo (Porttier,2007). Si bien, los estudios hechos desde la perspectiva de la nutrición son contradictorios en términos de los efectos positivos de los caldos calientes, reafirman que las referencias acerca de las pautas que guían la elección de estos alimentos siguen la impronta social. Así, lo relativo al fío y el calor en los alimentos no son estados independientes, sino cualidades que expresan diferentes estados del cuerpo y su relación con la salud y enfermedad.

Entonces, por una parte, las prácticas alimentarias nos muestran las trayectorias históricas y su relación con los alimentos, y por otra, las condiciones más amplias en las que el consumo perdura o se modifica. La crisis sanitaria muestra como la comida caliente puede ser una forma de acción que se materializa en el propio cuerpo para enfrentar las incertidumbres de esta etapa. Al ver la enfermedad como proceso social, comprendemos que está articulada con otras dimensiones. (Laurell, 1981).

Los diferentes momentos colectivamente vividos en lo que va de la pandemia ocasionada por el COVID-19, nos remiten a la necesidad de ubicar la construcción de los sentidos socialmente atribuidos a este virus. Observar la alimentación de los grupos sociales en este contexto, por una parte, se convierte en un lente que 
nuevamente da cuenta del carácter social y biológico del proceso salud enfermedad. Por otra parte, nos permite construir y caracterizar el proceso salud- enfermedad como objeto de estudio a nivel empírico mediante la observación de diversas prácticas. (Op cit, 1981) Como señala Laurell, esta postura tiene implicaciones directas para la práctica sanitaria porque visualiza la problemática en forma distinta respecto de lo que se hace con una descripción biologista de las condiciones de salud.

\section{Referencias}

1. Pilcher J. Qué Vivan Los Tamales. México: Ciesas, Conaculta, Ed. La Reyna Roja; 2001

2. Bertrán M. Acercamiento Antropológico de la Alimentación y Salud en México. Physis Revista de Saúde Coletiva. 2010; 20(2):387-411. [Consulta 30 jun 2020]. Disponible en: scielo.br/pdf/physis/v20n2/a04v20n2.pdf

3. Mintz S. Dulzura y Poder. El Lugar del Azúcar en la Historia Moderna. México: Siglo XXI; 1996.

4. Moreno L. Reflexiones sobre el trayecto salud-padecimiento-enfermedadatención: una mirada socioantropológica. Salud pública México. 2007, 49(1): 63-70.

5. Devillard M. La Construcción De La Salud Y De La Enfermedad. Reís 1981. 51/90: 79-89.

6. Laplantine F.Antropología de la Enfermedad. Argentina: Ediciones Sol, 1999.

7. Castro R. La vida en la adversidad. El significado de la salud y la enfermedad en la pobreza. Cuernavaca, Morelos: CRIM, 2000

8. Pérez $\mathrm{H}$. Vínculos entre cocina y tradición oral en patrimonio cultural y turismo. 2001. [Consulta 30 jun 2020]. Disponible en: https://patrimonioculturalyturismo.cultura.gob.mx/publi/Cuadernos_19_nu m/cuaderno7.2.pdf

9. Menéndez E. Autoatención de los Padecimientos y Algunos Imaginarios Antropológicos.Desacatos. 2018,58:104-113.

10. Marcell A. La comida y los recetarios como parte de un proceso cultural en patrimonio cultural y turismo. 2003 [Consulta 1 jul 2020]. Disponible en: https://patrimonioculturalyturismo.cultura.gob.mx/publi/Cuadernos_19_nu $\mathrm{m} /$ cuaderno7.2.pdf

11.López A. Cuerpo Humano e Ideología. Las Concepciones de los Antiguos nahuas. México: UNAM; 2004. 
12. Ingham J. On Mexican Folk Medicine. American Anthropologist. Febrero 1970; 79.

13. Vargas A, Casillas L. Comer, beber, cuerpo y cosmovisión, un viaje de ida y vuelta. Revistas unam. 2008, 42:87-115 [Consulta 2 jul 2020]. Disponible en: http://www.revistas.unam.mx/index.php/antropologia/article/view/18223

14.Turner, B. El Cuerpo y la Sociedad. México: FCE; 1989.

15. Conor K. Beber caldo de huesos: ¿es benéfico o solamente es una moda?.2018 [Consulta el 1 jul 2020]. Disponible

en: https://nutritionstudies.org/es/beber-caldo-de-huesos-es-benefico-osolamente-es-una-moda/

16.Saketkhoo K, Januszkiewicz A, Sackner MA. Effects of drinking hot water, cold water, and chicken soup on nasal mucus velocity and nasal airflow resistance. Chest. 1978; 74(4): 408-410 [Consulta 1 jul 2020].Disponible en: https://journal.chestnet.org/article/S0012-3692(15)37387-6/fulltext

17.Rosner F. Therapeutic Efficacy of Chiken Soup. Chest. 1980; 78(4):672-674. [Consulta 1 jul 2020]; Disponible en: https://journal.chestnet.org/article/S0012-3692(16)40246-1/abstract

18. Rennard B, Ertl R, Gossman G . Chicken Soup Inhibts Neutrophil Chemostaxis in Vitro. Chest. 2000;118(4):1150-1157 [Consulta 2 jul 2020]. Disponible en: https://journal.chestnet.org/article/S0012-3692(15)377217/abstract

19. Monro J, Leon R, Puri B. The risk of lead contamination in bone broth diets. NIH. 2013;80(4):389-90 [Consultado 30 jun 2020].

Disponible en: https://pubmed.ncbi.nlm.nih.gov/23375414/\#: :text=However\% 2C\%20bones\%20are\%20known\%20to,of\%20being\%20contaminated\%20with $\% 20 l e a d$.

20. Heid M. Science can't explain why everyone is drinking bone broth. 2016 [Consulta 30 jun 2020].Disponible en : https://time.com/4159156/

21.Rennard S, Kalil A, Casaburi R. Chicken Soup in the Time of COVID. Chest. 2020; 0:2 [Consulta 1 jul 2020]. Disponible en https://journal.chestnet.org/article/S0012-3692(20)30870-9/abstract

22. Aguilar $P$. Cultura y alimentación. Aspectos fundamentales para una visión comprensiva de la alimentación humana. Elsevier-Anales de Antropología. 2014; 48(1):11-31 [Consulta 3 jul 2020]. Disponible en https://www.elsevier.es/es-revista-anales-antropologia-95-articulo-culturaalimentacion-aspectos-fundamentales-una-S0185122514704874

23. Estrada M. Convivencia forzosa Experiencias familiares durante la emergencia sanitaria por el virus de la influenza humana $A(\mathrm{H} 1 \mathrm{~N} 1)$ en la Ciudad de México. Desacatos. 2010;32: 109-118. [Consulta 3 jul 2020]. Disponible en: http://desacatos.ciesas.edu.mx/index.php/Desacatos/article/view/385/263

24.Laurell C. La Salud-Enfermedad Como Proceso Social. Cuadernos Médico Sociales.1982;19:2-11. 